\title{
Arginase Inhibition Activity of Stem Bark Extract of Caesalpinia pulcherrima
}

\author{
Lutfi Tsara Zalsabela, Berna Elya*, Arikadia Noviani \\ Department of Pharmacognosy and Phytochemistry, Faculty of Pharmacy, Universitas Indonesia, Depok 16424 West Java, INDONESIA.
}

\begin{abstract}
Background: Inhibition of arginase activity can ameliorate endothelial dysfunction in vascular system which can cause some cardiovascular diseases. This study was aimed to test the arginase activity inhibition of n-hexane, ethyl acetate, and methanol extract of C. pulcherrima (L.) Sw. stem bark and determine total flavonoid content of the most active extract. Methods: C. pulcherrima (L.) Sw. stem bark was extracted using multistage reflux. In vitro arginase activity inhibition was done using $1 \mathrm{U} / \mathrm{mL}$ enzyme concentration and $570 \mathrm{mM}$ substrate concentration. The product was measured by microplate reader of wavelength $430 \mathrm{~nm}$. Results: Methanolic extract showed to be the most active extract in the test. $I C_{50}$ value of methanolic extract was $21.969 \mu \mathrm{g} / \mathrm{mL}$ which was higher than standard N(omega)-hydroxy-nor-L-arginine acetate (nor-NOHA acetate) that had $I_{50}$ value of $3.994 \mu \mathrm{g} / \mathrm{mL}$. The result of total flavonoid content determination of methanol extract by colorimetric $\mathrm{AlCl}_{3}$ was $3.943 \mathrm{mgQE} / \mathrm{gram}$ extract. Phytochemical screening shows that methanol extract of
\end{abstract}

C. pulcherrima (L.) Sw. stem bark contains flavonoids, tannins, saponins, and triterpenoids. Conclusion: Methanol extract of C. pulcherrima (L.) Sw. had significant inhibitory activity of arginase and can be used as a potential source for the development of arginase inhibitor.

Key words: Arginase, Caesalpinia pulcherrima (L.) Sw. stem bark, Total flavonoid content, Phytochemical screening

\section{Correspondence}

Berna Elya, Department of Pharmacognosy-Phytochemistry, Faculty of Pharmacy, University of Indonesia, Depok 16424 West Java, INDONESIA.

Phone: +62 81314161497

Email: berna.elya@farmasi.ui.ac.id, icapps2017.farmasiui@gmailcom

DOI: 10.5530/jyp.2018.2s.22

\section{INTRODUCTION}

Arginase (L-arginine amidinohydrolase) is an enzyme that catalyzes the hydrolysis of L-arginine to produce L-ornithine and urea. ${ }^{1}$ Endothelial nitric oxide synthase (eNOS) also uses L-arginine as a substrate to form nitric oxide (NO) and L-citrullin. ${ }^{2}$ Arginase upregulation can reduce the bioavailability of NO which can cause endothelial dysfunction..$^{3-4}$ Endothelial dysfunction is the root cause of some cardiovascular diseases including atherosclerosis, myocardial infarction, stroke, and hypertension. ${ }^{5}$ Some organic compounds are available as arginase inhibitors, including boronic acid derivates ( $S$-(2-boronoethyl)-L-cysteine) (BEC)), 2-(S)-amino-6-boronohexanoic acid $(\mathrm{ABH})$, and the arginine analogue (N (omega)-hydroxy-nor-L-arginine (nor-NOHA)). However, BEC and $\mathrm{ABH}$ have pharmacokinetic problems and potentially toxic in humans. ${ }^{6}$ While nor-NOHA has short half-life. ${ }^{7}$

Ethyl acetate extract of Caesalpinia sappan lignum showed $\mathrm{IC}_{50}$ value of $36.82 \mu \mathrm{g} / \mathrm{mL}$ to arginase II. Brazilin, the purified compounds of C. sappan, belonged to homoisoflavonoids, have endothelial dependent vasorelaxant activity. ${ }^{8-9}$ In other studies, flavanones belonged to flavonoids isolated from Scutellaria indica were able to inhibit arginase activity with an $\mathrm{IC}_{50}$ of $25.1 \mu \mathrm{M} .{ }^{10}$ Flavonoids can also be found in C. pulcherrima (L.) Sw. ${ }^{11-12}$ C. pulcherrima (L.) Sw. displays activity as emmenagogue and can treat several diseases such as asthma, ulcers, fever, tumors, and skin diseases. ${ }^{12-13}$ In this study, we investigated the inhibition of arginase activity of n-hexane, ethyl acetate, and methanol extract of C. pulcherrima (L.) Sw. stem bark by urea measurement as the result of arginase and L-arginine reaction.

\section{MATERIALS AND METHODS}

\section{Materials}

The stem bark of C. pulcherrima (L.) Sw. was obtained from the Center for Plant Conservation-Bogor Botanical Garden. All other chemical and reagent were source commercially. nor-NOHA acetate from Cayman (USA), quercetin from Sigma Aldrich (India), and arginase, L-arginine, maleic acid, and $\mathrm{MnSO}_{4}$ from Sigma Aldrich (Singapore). Urea kit assay was obtained from Abnova (Taiwan), n-hexane, ethyl acetate, and methanol from Merck (Germany).

\section{Preparation of $C$. pulcherrima stem bark extract}

Stem bark of C. pulcherrima was collected in December 2016, obtained and identified by microscopic and morphology characteristics at the Center for Plant Conservation-Bogor Botanical Gardens.

\section{Extraction}

Dried powdered stem bark (150 g) was extracted by multistage reflux and then evaporated.

\section{Arginase Activity Inhibition Test}

The inhibition activity was determined by methods modified from the protocols described in the Sigma Aldrich (EC 3.5.3.1). Ten microliters of extract sample were mixed with 15 microliters of arginase $1 \mathrm{U} / \mathrm{mL}, 20 \mu \mathrm{L}$ $\mathrm{L}$-arginine $570 \mathrm{mM}$, and preincubated at $37^{\circ} \mathrm{C}$ for $30 \mathrm{~min}$. One hundred of urea assay reagent was then added and the mixture incubated at room temperature for one hour. Arginase activity was determined on a microplate reader (Epoch, USA) by measuring the quantity of urea released 
from arginase. nor-NOHA was used as a positive control for arginase inhibition. The concentration of the extract that inhibited $50 \%$ of arginase activity under the test condition was defined as $\mathrm{IC}_{50}$.

\section{Determination of Total Flavonoid Content}

Total flavonoid content was determined according to the methods in Pharmacopoeia Herbal Indonesia Supplement III. ${ }^{14}$ Quercetin was used as a standard to develop calibration curves spanning the concentrations of 3, 4, 5, 6, 7 and $8 \mu \mathrm{g} / \mathrm{mL}$ in ethanol (AR). To determine the flavonoid content, a solution of quercetin or extract in $0.5 \mathrm{~mL}$ was added to a test tube. The solution then mixed with $1.5 \mathrm{~mL}$ ethanol (AR); $0.1 \mathrm{~mL}$ of $10 \%$ $\mathrm{AlCl}_{3}$ solution; $0.1 \mathrm{~mL} 1 \mathrm{M}$ sodium acetate and $2.8 \mathrm{~mL}$ distilled water. For sample blank, the sample containing the listed components except $\mathrm{AlCl}_{3}$ was replaced by the same quantity of distilled water. The mixture was centrifuged at $1000 \mathrm{rpm}$ for $10 \mathrm{~min}$ and then incubated at room temperature for $30 \mathrm{~min}$. Absorbance was measured using UV-Vis spectrophotometer (Shimadzu 265, Japan) at $\lambda 437.5 \mathrm{~nm}$. The total flavonoid content was derived from the calibration curve.

\section{Phytochemical Screening}

Qualitative method of phytochemical screening for active extract was undertaken using the alkaloid test with Mayer, Dragendroff, and Wagner reagents; ${ }^{15-17}$ flavonoids test with Willstatter reaction; ${ }^{16}$ tannins test with gelatin test and ferrous (III) chloride; ${ }^{17-18}$ saponins test with honeycomb froth test; ${ }^{16}$ quinones with $\mathrm{NaOH},{ }^{15}$ steroids, and triterpenoids with Liebermann-Burchard reagent. ${ }^{17}$

\section{RESULTS}

\section{Extraction}

Extraction is a method to separate the active compound of the plant using a selective solvent through a particular procedure. The stem bark of C. pulcherrima (L.) Sw. was successfully extracted using the reflux method. The yield depended on the solvents used. From 150 gram of stem bark, the yields obtained were $2.53 \mathrm{~g}(1.68 \%)$ with n-hexane, $7.41 \mathrm{~g}$ (4.93\%) with ethyl acetate, and $22.37 \mathrm{~g}(14.89 \%)$ with methanol.

\section{Arginase Activity Inhibition Test}

Inhibitions of arginase activity of n-hexane, ethyl acetate, and methanol extract with L-arginine as the substrate were compared with standard, nor-NOHA acetate. The initial screening with sample concentration $100 \mu \mathrm{g} / \mathrm{mL}, \mathrm{n}$-hexane extract has no arginase inhibition, ethyl acetate extract has $23.73 \%$ of arginase inhibition actity, and methanol extract has $79.13 \%$ of arginase inhibition activity. The $\mathrm{IC}_{50}$ value of methanol extract of C. pulcherrima (L.) Sw. was $21.969 \mu \mathrm{g} / \mathrm{mL}$ and $3.994 \mu \mathrm{g} / \mathrm{mL}$ for nor-NOHA acetate.

\section{Total Flavonoid Content Determination on The Most Active Extract}

Total flavonoid content was determined in the most active extract, methanol extract. Methanol as the polar solvent dissolve polar compound like flavonoids, so total flavonoid content determination was the one of many ways provided. The standard curve for pure quercetin absorbance vs concentration was linear $\left(r^{2}=0,9989\right)$. This was used to estimate the total flavonoid content of the extract. The total flavonoid content of the methanol extract was determined to be $3.943 \mathrm{mg}$ QE with pure quercetin as a standard through the method has been explaned above.

\section{Phytochemical Screening}

Phytochemical screening was used to know what was the phytochemical compound contained in the extract. Phytochemical screening reviewed from the methanol extract can be showed from Table 1.

\begin{tabular}{cc} 
Table 1: The phytochemical compound result of methanol extract \\
\hline Phytochemical compounds & Methanol extract \\
\hline Alkaloids & - \\
Flavonoids & + \\
Tannins & + \\
Saponins & + \\
Quinones & - \\
Steroids & - \\
Triterpenoids & + \\
\hline
\end{tabular}

\section{DISCUSSION}

\section{Extraction}

The multistage reflux extraction method aims to separate the content of the bark of C. pulcherrima (L.) Sw. based on polarity. Reflux method is used to speed up the extraction time. The solvent of each solvent is carried out as much as three times in order to maximize the yield extraction. The more polar extracting solvent, the greater the yield. The greatest yield, $14.89 \%$ showed by using methanol as a solvent. However, the yields was low eventhough the sample was extracted with methanol. Nevertheless, the amount extracted was enough for subsequent experiments.

\section{Arginase Activity Inhibiton Test}

Inhibitions of arginase activity using L-arginine as a substrat can reduce the urea production. Urea as aresult of arginase and L-arginine reaction was measured using microplate reader and used as a mark of arginase activity inhibition. The arginase activity inhibition of methanol extract was determined by methods modified from the protocols described in the Sigma Aldrich, while the arginase activity inhibition of nor-NOHA acetate was determined by method combinations of product information of nor-NOHA acetate and arginase protocols. The result shows that n-hexane has no arginase inhibition activity, while ethyl acetate and methanol extract has $23.73 \%$ and $79.13 \%$ respectively with sample concentration $100 \mu \mathrm{g} / \mathrm{mL}$. The $\mathrm{IC}_{50}$ value test has done only on methanol extract as the most active extract and then was compared with $\mathrm{IC}_{50}$ value of the standard compound, nor-NOHA acetate. The $\mathrm{IC}_{50}$ value of methanol extract of C. pulcherrima (L.) Sw. was $21.969 \mu \mathrm{g} / \mathrm{mL}$ and $3.994 \mu \mathrm{g} / \mathrm{mL}$ for nor-NOHA acetate. So the methanol extract, the most efficient extracting solvent, was only $20 \%$ as effective as the nor-NOHA acetate solution in inhibitory activity.

\section{Total Flavonoid Content Determination on The Most Active Extract}

It is considered that polar compounds from methanol extract play the role in arginase inhibition activity. The one of polar chemical compounds was flavonoid. Flavonoid was reported can be found in C. pulcherrima (L.) Sw. Total flavonoid content deternination was the one of many ways to know how many flavonoid in extract. Total flavonoid content determination was done through colorimetric $\mathrm{AlCl}_{3}$ method and using quercetin as a standard. Based on the absorbance reading using UV-Vis spectrophotometer of the extract solution tested the concentration was read from the standard curve. Total flavonoid content was estimated from the following formula: ${ }^{19}$

$$
\text { Total flavonoid content }=\frac{\mathrm{R} \times \mathrm{DF} \times \mathrm{V}}{\mathrm{W}}
$$

where $\mathrm{R}=$ the quercetion concentration in the extract, $\mathrm{DF}=$ dilution factor, $\mathrm{V}=$ volume, $\mathrm{W}=$ weight of extract. 
Total flavonoid content determination was expressed in QE (Quercetin equivalent). It was defined as the milligram equivalent of quercetin in 1 gram of sample. Methanol extract as the most active extract has total flavonoid content $3.943 \mathrm{mg}$ QE. Although total flavonoid content in the methanol extract was low, flavonoid present in the extract may contribute to inhibition of arginase activity, but it also can not be denied that other compounds may also play a role in inhibiting arginase activity.

\section{Phytochemical Screening}

Phytochemical screening reviewed that the methanol extract contains flavonoid, tannin, saponin, and triterpenoid. It is likely that flavonoids and tannins play an important role in the inhibition of arginase activity. In other studies, flavanones isolated from Scutellaria indica were able to inhibit arginase activity with an $\mathrm{IC}_{50}$ of $25.1 \mu \mathrm{M} .{ }^{20}$ Apart from flavonoid, tannin that was detected during phytochemical screening and probably also contributed to the arginase inhibition activity. It has been reported that (-)-epicatechin-3-gallate, a compound belonging to the tannin group, inhibited arginase activity with an $\mathrm{IC}_{50}$ of $3.8 \mu \mathrm{M} .{ }^{20}$ To prove what compounds that play a role in inhibition of arginase activity required further research including fractionation, isolation, and compound characterization.

\section{CONCLUSION}

The bark of C. pulcherrima (L.) Sw. had the inhibitory effect on arginase activity.

\section{ACKNOWLEDGEMENT}

The authors are highly thankful to Universitas Indonesia who had given a financial support for this research, particularly for PITTA Reseach Grants 2017.

\section{CONFLICT OF INTEREST}

The authors declare no conflict of interest.

\section{ABBREVIATIONS}

C. pulcherrima: Caesalpinia pulcherrima; nor-NOHA acetate: $\mathrm{N}$ (omega)-hydroxy-nor-L-arginine acetate; $\mathbf{A l C l}_{3}$ : Alumunium Chloride; QE: Quercertin Equivalent; eNOS : Endothelial Nitric Oxide Synthase; NO: Nitric Oxide; BEC: (S-(2-boronoethyl)L-cysteine); ABH: 2-(S)-amino-6-boronohexanoic acid; AR: Analytical Reagent; UV: Ultra Violet; $\mathrm{NaOH}$ : Sodium Hydroxide.

\section{SUMMARY}

Methanol extract as the most active extract from Caesalpinia pulcherrima stem bark had $\mathrm{IC}_{50}$ value of $21.969 \mu \mathrm{g} / \mathrm{mL}$ for arginase activity inhibition

\section{REFERENCES}

1. Kepka-Lenhart D, Ash DE, Morris SM. Determination of Mammalian Arginase Activity. Methods Enzymol. 2008;440:221-30. doi:10.1016/S00766879(07)00813-0.

2. Kietadisorn R, Juni RP, Moens AL. Tackling endothelial dysfunction by modulating NOS uncoupling: new insights into its pathogenesis and therapeutic possibilities. Am J Physiol Endocrinol Metab. 2012;302(5):E481-95. doi:10.1152/ajpendo.00540.2011.

3. Lundberg JO, Gladwin MT, Weitzberg E. Strategies to increase nitric oxide signalling in cardiovascular disease. Nat Rev Drug Discov. 2015;14(9):623-41. doi:10.1038/nrd4623.

4. Kövamees O, Shemyakin A, Pernow J. Effect of arginase inhibition on ischemiareperfusion injury in patients with coronary artery disease with and without diabetes mellitus. Gallyas F, ed. PLoS ONE. 2014;9(7):e103260. doi:10.1371/ journal.pone.0103260

5. Madigan M, Zuckerbraun B. Therapeutic potential of the nitrite-generated NO pathway in vascular dysfunction. Frontiers in Immunology. 2013;4:174. doi:10.3389/fimmu.2013.00174.

6. Ivanenkov YA, Chufarova NV. Small-molecule arginase inhibitors. Pharm Pat Anal. 2014;3(1):65-85. doi:10.4155/ppa.13.75.

7. Havlinova Z, Babicova A, Hroch M, Chladek J. Comparative pharmacokinetics of $N(\omega)$-hydroxy-nor-L-arginine, an arginase inhibitor, after single-dose intravenous, intraperitoneal and intratracheal administration to brown Norway rats. Xenobiotica. 2013;43(10):886-94. doi:10.3109/00498254.2013.780672.

8. Shin W, Cuong TD, Lee JH, Min B, Jeon BH, Lim HK, et al. Arginase inhibition by ethylacetate extract of Caesalpinia sappan lignum contributes to activation of endothelial nitric oxide synthase. Korean J Physiol Pharmacol. 2011;15(3):123-8. doi:10.4196/kjpp.2011.15.3.123.

9. Zanin JL, De Carvalho BA, Martineli PS, Dos Santos MH, Lago JH, Sartorelli P, et al. The genus Caesalpinia L. (Caesalpiniaceae): Phytochemical and pharmacological characteristics. Molecules. 2012;17(7):7887-902. doi:10.3390/molecules 17077887

10. Kim SW, Cuong TD, Hung TM, Ryoo S, Lee JH, Min BS. Arginase II inhibitory activity of flavonoid compounds from Scutellaria indica. Arch Pharm Res. 2013;36(8):922-6. doi:10.1007/s12272-013-0125-3.

11. Fusi F, Ferrara A, Koorbanally C, Crouch NR, Mulholland DA, Sgaragli G. Vascular myorelaxing activity of isolates from South African Hyacinthaceae partly mediated by activation of soluble guanylyl cyclase in rat aortic ring preparations. J Pharm Pharmacol. 2008;60(4):489-97. doi:10.1211/jpp.60.4.0012.

12. Das B, Thirupathi P, Ravikanth B, Aravind Kumar R, Sarma AV, Basha SJ. Isolation, synthesis, and bioactivity of homoisoflavonoids from Caeasalpinia pulcherrima. Chem Pharm Bull (Tokyo). 2009;57(10):1139-41.

13. Zhipare AN, Mute VM, More AS, Awari DM. In-vitro study of antioxidant activity of stem bark of Caesalpinia pulcherrima Linn. World J Pharm Pharm Sci. 3(2):2079-89.

14. Direktorat Jenderal Bina Kefarmasian dan Alat Kesehatan. Suplemen III farmakope herbal Indonesia edisi I. Jakarta: Kementrian Kesehatan Republik Indonesia. 2013.

15. Doughari JH. Phytochemicals: Extraction methods, basic structures and mode of action as potential chemotherapeutic agents. In: Rao V, editors. Phytochemicals - a global perspective of their role in nutrition and health. Shanghai (China): Intech. 2012:1-33.

16. Obouayeba AP, Diarrassouba M, Soumahin EF, Kouakou H. Phytochemical Analysis, Purification and Identification of Hibiscus Anthocyanins. J Pharm Chem Biol Sci. 2015;3(2):156-68.

17. Iqbal E, Salim KA, Lim LB. Phytochemical screening, total phenolics and antioxidant activities of bark and leaf extracts of Goniothalamus velutinus (Airy Shaw) from Brunei Darussalam. Journal of King Saud University - Science. 2015;27(3):224-32.

18. Banu KS, Catherine L. General techniques involved in phytochemical analysis. International Journal of Advanced Research in Chemical Science. 2015;2(4):25-32.

19. Bhaigyabati T, Devi PG, Bag GC. Total flavonoid content and antioxidant activity of aqueous rhizome extract of three Hedychium Species of Manipur valley. Res J Pharm Biol Chem Sci. 2014;5(5):970-6.

20. Dos Reis MB, Manjolin LC, Maquiaveli Cdo C, Santos-Filho OA, Da Silva ER. Inhibition of Leishmania (Leishmania) amazonensis and rat arginases by green tea EGCG, (+)-catechin and (-)-epicatechin: A comparative structural analysis of enzyme-inhibitor interactions. PLoS One. 2013;8(11):e78387. doi:10.1371/journal. pone.0078387. 